\title{
Predictors of total morbidity burden on days 3,5 and 8 after cardiac surgery
}

Julie Sanders ${ }^{1,2}$, Jackie Cooper ${ }^{3}$, Michael G. Mythen ${ }^{2,4}$ and Hugh E. Montgomery ${ }^{2^{*}}$

\begin{abstract}
Background: Post-operative morbidity affects up to $36 \%$ of cardiac surgical patients. However, few countries reliably record morbidity outcome data, despite patients wanting to be informed of all the risks associated with surgery. The Cardiac Post-Operative Morbidity Score (C-POMS) is a new tool for describing and scoring (0-13) total morbidity burden after cardiac surgery, derived by noting the presence/absence of 13 morbidity domains on days 3, 5, 8 and 15 . Identifying modifiable C-POMS risk factors may suggest targets for intervention to reduce morbidity and healthcare costs. Thus, we explored the association of C-POMS with previously identified predictors of post-operative morbidity.

Methods: A systematic literature review of pre-operative risk assessment models for post-operative morbidity was conducted to identify variables associated with post-operative morbidity. The association of those variables with C-POMS was explored in patients drawn from the original C-POMS study $(n=444)$.

Results: Seventy risk factors were identified, of which 56 were available in the study and 49 were suitable for analysis. Numbers were too few to analyse associations on D15. Thirty-three (67.3\%) and 20 (40.8\%) variables were associated with C-POMS on at least 1 or 2 days, respectively. Pre-operative albumin concentration, left ventricular ejection fraction and New York Heart Association functional class were associated with C-POMS on all days. Of the 16 independent risk factors, pre-operative albumin and haemoglobin concentrations and weight are potentially modifiable.

Conclusions: Different risk factors are associated with total morbidity burden on different post-operative days. Preoperative albumin and haemoglobin concentrations and weight were independently predictive of post-operative total morbidity burden suggesting therapeutic interventions aimed at these might reduce both post-operative morbidity risk and health-care costs in patients undergoing cardiac surgery.
\end{abstract}

Keywords: Risk factor, Cardiac surgery, Morbidity outcome, C-POMS

\section{Background}

In surgery, post-operative mortality is the most commonly cited outcome variable and to date has been considered the standard measure of quality of care. However, while cardiac operative mortality has fallen (currently $2.1 \%$ in the USA (Society of Thoracic Surgeons) and $1.5 \%$ in the UK (Bridgewater et al. 2008)), post-operative morbidity remains common affecting between $4.3 \%$ (Fortescue et al. 2001) and 36\% (Magovern et al. 1996) of cardiac patients and significantly prolonging length of stay (LOS) (Dupuis et al. 2001). Such morbidity has substantial impact on healthcare resources, with the average in-hospital incremental cost of experiencing any complication at

\footnotetext{
* Correspondence: h.montgomery@ucl.ac.uk

${ }^{2}$ Institute for Sport, Exercise and Health, University College London, 1st Floor

170 Tottenham Court Rd, London W1T 7HA, UK

Full list of author information is available at the end of the article
}

$\$ 15,468$ per patient (Brown et al. 2008). Thus, strategies to identify and reduce post-operative morbidity might reduce both patient well-being and healthcare costs.

However, few countries reliably record morbidity outcome data (Weiser et al. 2008). Previously, morbidity definitions included death (Fortescue et al. 2001), focused on major morbid events only (Huijskes et al. 2003), or used surrogate markers of morbidity (for example post-operative LOS (Magovern et al. 1996; Dupuis et al. 2001)). Likewise, many national cardiac surgical registers collect only 30-day mortality outcome and in some cases hospital LOS. Contrastingly, although the Society of Thoracic Surgeons national database contains 49 variables related to post-operative events, a composite metric aimed at defining post-operative 
morbidity includes in-hospital death and only five severe specific morbidities (Shahian et al. 2010).

The Cardiac Post-Operative Morbidity Score (CPOMS) (Sanders et al. 2012) is a simple, validated score (0-13) by which to identify and quantify total morbidity burden (TMB) after adult cardiac surgery (Table 1) on multiple post-operative days. We have previously reported that every unit increase in C-POMS is associated with a 1.7, 2.2 and 4.5-day increase in subsequent LOS on days 3 (D3), 5 (D5) and 8 (D8) (Sanders et al. 2012), which has significant associated health-care costs, organisational and resource implications. Efforts to identify the risk factors associated with this post-operative TMB score may not only assist in identifying modifiable risk factors for which therapeutic interventions can be implemented to reduce the post-operative risk, but also serve to potentially further validate C-POMS as a useful clinical tool in cardiac surgery post-operative morbidity assessment.

Thus, we sought to identify risk factors associated with post-operative TMB, as assessed by the C-POMS tool, with an aim of identifying potentially modifiable risk factors that could be therapeutic targets to reduce postoperative cardiac surgical morbidity.

\section{Methods}

The National Research Ethics Committee LondonBentham (Chair Professor David Katz) gave ethics permission for this study (protocol amendment 7) on 6 September 2011 (reference 04/Q0502/73). All patients included in this study gave written informed consent to participate.

\section{Participants}

Patients were drawn from the development and validation of the C-POMS study, detailed elsewhere (Sanders et al. 2012). In brief, patients undergoing any form of adult cardiac surgery (excluding cardiac surgery for a congenital heart condition or a cardiomyopathy) between January 2005 and November 2007 at the Heart Hospital, University College London Hospitals NHS Trust, UK, and who gave written informed consent were eligible for inclusion. Excluded were those $<18$ years old, undergoing emergency surgery, who were enrolled in clinical intervention trials or who died within 5 days of surgery.

\section{C-POMS}

The development and validation of the C-POMS tool and score is detailed elsewhere (Sanders et al. 2012). In brief, The McMaster Framework (Kirshner and Guyatt, 1985; Guyatt et al. 1992) for constructing and assessing health indices for discriminative instruments, comprising item selection, item scaling, item reduction and determination of reliability and validity processes, was used.
The C-POMS represents TMB as a summary score (0-13), derived by noting the presence or absence of 13 morbidity domains on days 3 (D3), 5 (D5), 8 (D8) and 15 (D15) after cardiac surgery (Table 1 ).

\section{Pre- and intra-operative clinical data}

A protocol development group, comprising 15 representatives from cardiac nursing, surgery, intensive care and anaesthesia, determined the pre-, intra-, and postoperative variables to be collected prior to commencement of the study. In brief, these included demographic details, past and current medical history, coronary heart disease risk factors, routine biochemistry and haematology measurements, anaesthesia details, operative details and a detailed record of the first $24 \mathrm{~h}$ in the intensive care unit. Variables were either obtained from the Society of Cardiothoracic Surgery national database or prospectively from the medical and nursing records by a dedicated, experienced research nurse using a standardised proforma.

\section{Identification and categorisation of potential risk factors}

To identify pre-operative risk prediction models of postoperative morbidity following cardiac surgery, a systematic literature review was conducted using the basic framework for conducting systematic reviews from the Centre for Reviews and Dissemination (Dissemination Centre for Reviews and Dissemination 2001). Three methodological quality filters were utilised. Firstly, the study population was defined as an adult population undergoing any form of cardiac surgery (excluding transplantation and grown-up congenital heart surgery); only methodologies that constructed a pre-operative risk assessment tool were included; valid outcomes were mortality and morbidity. There were no exclusions on the basis of the definition of either outcome. Search terms included cardiac surgery score, cardiac surgery risk score, pre-operative risk; cardiac surgery and risk prediction score; cardiac surgery, coronary artery bypass graft (CABG), surgery morbidity and surgery outcome. In addition to publication databases (the National Centre for Biotechnology Information, Entrez retrieval system and the Web of Science ISI Citation Databases), sources of on-going and recently completed studies (The National Research Register, The Cochrane Library of Systematic Reviews) were also interrogated to identify eligible papers. In total, the abstracts of 1067 papers were scrutinised. Backward and forward citation searches were conducted on all identified eligible papers. Overall, a total of 21 pre-operative risk prediction models were identified.

All pre- and intra-operative variables obtained within the C-POMS study were classified with respect to these models into one of two tiers (results in Additional file 1): 
Table 1 The Cardiac Post-Operative Morbidity Score (C-POMS) (as reported in Sanders et al. 2012)

\begin{tabular}{|c|c|}
\hline Morbidity type & C-POMS criteria \\
\hline Pulmonary & $\begin{array}{l}\text { Presence of one or more of the following: } \\
\text { - New requirement for oxygen or respiratory } \\
\text { support (including nebuliser therapy or request } \\
\text { for chest physiotherapy on or after D5) } \\
\text { - Pleural effusion requiring drainage }\end{array}$ \\
\hline Infectious & $\begin{array}{l}\text { Presence of one or more of the following: } \\
\text { - Currently on antibiotics } \\
\text { - Has had a temperature of }>38^{\circ} \mathrm{C} \text { in the last } 24 \mathrm{~h} \\
\text { - Has a white cell count/CRP level requiring } \\
\text { in-hospital review or treatment }\end{array}$ \\
\hline Renal & $\begin{array}{l}\text { Presence of one or more of the following: } \\
\text { - Presence of decreased urine output requiring } \\
\text { intervention (including IV furosemide) } \\
\text { - Increased serum creatinine (>30\% from } \\
\text { - Ure-operative level) } \\
\text { - Urinary catheter in situ } \\
\text { - Sew urinary incontinence }\end{array}$ \\
\hline Gastrointestinal & $\begin{array}{l}\text { Presence of one or more of the following: } \\
\text { - Unable to tolerate an enteral diet for any reason } \\
\text { including nausea, vomiting and abdominal } \\
\text { distension } \\
\text { - Nasogastric tube } \\
\text { - Diagnosis of a gastrointestinal bleed } \\
\text { - Diarrhoea }\end{array}$ \\
\hline Cardiovascular & $\begin{array}{l}\text { Presence of one or more of the following: } \\
\text { - The use of inotropic therapy for any } \\
\text { cardiovascular cause } \\
\text { - Pacing wires (on or after D5) } \\
\text { and/or requiring temporary or new } \\
\text { permanent pacing } \\
\text { - Diagnostic tests or therapy within the last } 24 \mathrm{~h} \\
\text { for any of the following: (1) new Ml or ischaemia, } \\
\text { (2) hypotension (requiring fluid therapy, } \\
\text { pharmacological therapy or omission of } \\
\text { pharmacological therapy, (3) atrial or ventricular } \\
\text { arrhythmias, (4) cardiogenic pulmonary oedema, } \\
\text { thrombotic event (requiring anticoagulation), } \\
\text { (5) hypertension (pharmacological therapy } \\
\text { or omission of pharmacological therapy) }\end{array}$ \\
\hline
\end{tabular}

Neurological New neurological deficit (including confusion, delirium, coma, lack of coordination, drowsy/slow to wake, poor swallow, blurred vision, sedated, changing loss of consciousness)

Haematological Presence of one or more of the following: - Untherapeutic INR requiring pharmacological therapy or omission of pharmacological therapy - Requirement for any of the following within the last 24 h: packed erythrocytes, platelets, fresh-frozen plasma, or cryoprecipitate

Wound Presence of one or more of the following: - Wound dehiscence requiring surgical exploration or drainage of pus from the operation wound with or without isolation of organisms

- Chest drains

- Wound pain significant enough to require continuing or escalating analgesic intervention

Pain Postoperative pain significant enough to require parenteral opioids and/or continuing or additional analgesia

Endocrine New or additional requirements for blood sugar management
Table 1 The Cardiac Post-Operative Morbidity Score (C-POMS) (as reported in Sanders et al. 2012) (Continued)

\begin{tabular}{ll}
\hline Electrolyte & $\begin{array}{l}\text { Electrolyte (including sodium, urea, phosphate) } \\
\text { imbalance requiring oral or intravenous } \\
\text { intervention (not including potassium as included } \\
\text { in renal category) }\end{array}$ \\
Review & $\begin{array}{l}\text { Remaining in hospital for further review, investigation } \\
\text { and/or procedure }\end{array}$ \\
Assisted & $\begin{array}{l}\text { A new or escalated post-operative requirement } \\
\text { ambulation }\end{array}$ \\
$\begin{array}{l}\text { for mobility assistance (including wheelchair, } \\
\text { crutches, zimmer frame, walking sticks or assistance) }\end{array}$ \\
$\begin{array}{l}\text { CRP C-reactive protein, IV intravenous, MI myocardial infarction, INR international } \\
\text { normalised ratio, OPA out-patient appointment, OT occupational therapy }\end{array}$
\end{tabular}

Tier 1 variables were those which had been associated with morbidity risk in three or more separate papers (significant evidence), while tier 2 variables were those identified in one or two papers (some evidence).

\section{Statistical methods}

Baseline characteristics are presented as mean \pm SD or $n$ (\%). For the univariate analysis, C-POMS is presented as the median score and compared over categories using the Kruskal-Wallis test. The association of continuous variables with C-POMS was assessed using the Spearman rank correlation. For the multivariate analysis, variables with $p<0.25$ on univariate analysis were considered for inclusion into the models and stepwise regression with backwards elimination and a threshold of $p<0.05$ was run. Validation of the models was performed by running 1000 bootstrap samples. Variables selected in at least $60 \%$ of the bootstrap samples were included in the final model. For the data on all time points combined, the models used were random intercept models with time fitted as a fixed effect.

\section{Results}

\section{Baseline participant characteristics}

Of 748 potentially eligible patients undergoing cardiac surgery, 520 (69.5\%) were screened (due to researcher availability) and $464(89.2 \%)$ consented to participate. Fourteen participants subsequently became ineligible, leaving 450 who completed the study. Six participants declined for their data to be used outside the development of C-POMS.

Table 2 summarises participant characteristics. The majority were White British (379, 85.4\%), male (351, $79.1 \%$ ) with a mean age of 66.6 years (range 19-91 years). Most had triple vessel disease (243, 54.7\%), a good $(>50 \%)$ left ventricular ejection fraction (LVEF) (323, $74.1 \%$ ) and were of moderate mortality risk (mean EuroSCORE 4.1). The majority had elective surgery (69.6\%), using cardiopulmonary bypass $(412,93.4 \%)$ and stayed on intensive care unit (ICU) for an average of 2.0 days while remaining in the operating hospital for 
Table 2 Baseline characteristics $(n=444)$. All values $n(\%)$ unless otherwise stated

\begin{tabular}{|c|c|}
\hline & Frequency/ \\
\hline \multicolumn{2}{|l|}{ Demographics } \\
\hline Age (mean/years) & $66.6 \pm 10.7$ \\
\hline Female gender & $93(20.9)$ \\
\hline Ethnicity (White British) & $379(85.4)$ \\
\hline \multicolumn{2}{|l|}{ Medical history } \\
\hline Renal (dialysis) & $7(1.6)$ \\
\hline History of previous Ml & $148(33.3)$ \\
\hline Re-operation & $18(4.1)$ \\
\hline \multicolumn{2}{|l|}{ Symptoms } \\
\hline \multicolumn{2}{|l|}{ NYHA Class } \\
\hline I & $115(26.0)$ \\
\hline$\|$ & $205(46.3)$ \\
\hline III & $101(22.8)$ \\
\hline IV & $22(5.0)$ \\
\hline \multicolumn{2}{|l|}{ Cardiac risk factors } \\
\hline \multicolumn{2}{|l|}{ Smoking } \\
\hline Current & $49(11.0)$ \\
\hline Ex & $245(55.2)$ \\
\hline Never & $150(33.8)$ \\
\hline Hypertension & $303(68.2)$ \\
\hline Hypercholesteraemia & $343(77.4)$ \\
\hline Diabetes & $103(23.2)$ \\
\hline Body mass index $\left(\mathrm{kg} / \mathrm{m}^{2}\right) /$ mean & $28.5 \pm 5.6$ \\
\hline \multicolumn{2}{|l|}{ Examination and investigation } \\
\hline \multicolumn{2}{|l|}{ LVEF } \\
\hline Good & $323(74.1)$ \\
\hline Fair & $90(20.6)$ \\
\hline Poor & $23(5.3)$ \\
\hline \multicolumn{2}{|l|}{ Pre-operative risk assessment } \\
\hline EurOSCORE & $4.1 \pm 2.8$ \\
\hline \multicolumn{2}{|l|}{ Intra-operative details } \\
\hline Operative priority_elective & $309(69.6)$ \\
\hline \multicolumn{2}{|l|}{ Operation performed } \\
\hline CABG & $299(67.3)$ \\
\hline AVR & $61(13.7)$ \\
\hline MVR & $10(2.3)$ \\
\hline$C A B G+A V R$ & $36(8.1)$ \\
\hline$C A B G+M V R$ & $0(0.0)$ \\
\hline$A V R+M V R$ & $3(0.7)$ \\
\hline$C A B G+A V R+M V R$ & $2(0.5)$ \\
\hline Other & $33(7.4)$ \\
\hline Cardiopulmonary bypass used & $412(93.4)$ \\
\hline
\end{tabular}

Table 2 Baseline characteristics $(n=444)$. All values $n(\%)$ unless otherwise stated (Continued)

\begin{tabular}{ll}
\hline Outcome & \\
Length of ICU stay (mean/days) & $2.0 \pm 3.5$ \\
Return to theatre & $21(4.8)$ \\
Total length of hospital stay (mean/days) & $11.8 \pm 11.7$ \\
\hline
\end{tabular}

9.5 days. The observed in-hospital mortality rate was $1.3 \%$. Overall, $444(100.0 \%)$ were in-patients on D1 and D3, $420(94.6 \%)$ on D5, $178(40.1 \%)$ on D8 and 45 (10.1\%) on D15. Subsequent risk factor analysis was only appropriate on D3, D5 and D8 due to low numbers on D15.

\section{Tier 1 and 2 analysis}

Univariate analysis Fifty-six variables were identified in tiers 1 and 2 . The incidence of seven (12.5\%) preoperative variables (cardiogenic shock, catheter-induced coronary closure, intra-aortic balloon pump, intubation, permanent pacemaker, immunosuppressant medications and inotropes) was too small for analysis, resulting in 49 variables (23 tier 1; 26 tier 2$)$ for analysis. Thirty-three of the $49(67.3 \%)$ variables previously identified to be associated with post-operative morbidity were found to be associated with C-POMS on at least one post-operative day (Table 3). Of those, 10 variables were associated with C-POMS summary score on 1 day only, on either D3 (smoking, body mass index, urgency of operation, use of cardiopulmonary bypass, total drainage within the first $12 \mathrm{~h}$ and D1 inotropes) or D5 (ethnicity, neurological history, pre-operative heart rate and dialysis). No variables were solely predictive of D8 C-POMS summary score. Twenty variables $(40.8 \%)$ were associated with CPOMS summary score on 2 days, while 3 variables (preoperative albumin and New York Heart Association (NYHA) class and LVEF) were associated with C-POMS summary score on all days.

Overall, 8/23 (34.7\%) tier 1 variables and 8/26 (34.7\%) tier 2 variables were not associated with C-POMS summary score on any post-operative day (results in Additional file 2).

Multivariate analysis Of the 49 variables, 16 (32.7\%) were independent risk factors of C-POMS summary score on one or more post-operative days, while no variables were associated with C-POMS outcome on all three post-operative days (Table 4).

There were eight tier 1 variables, all of which (with the exception of renal dysfunction) were associated with TMB on D3. Diabetes, LVEF, CABG surgery and renal dysfunction were also associated with D5 C-POMS summary score. However, only tier 2 variables (pre-operative 
Table 3 Univariate analysis: tier 1 and 2 predictors of C-POMS summary score on D3, D5 and D8

\begin{tabular}{|c|c|c|c|c|c|c|}
\hline \multirow[t]{2}{*}{ Variable } & \multicolumn{2}{|l|}{ D3 $(n=441)$} & \multicolumn{2}{|l|}{ D5 $(n=419)$} & \multicolumn{2}{|l|}{$\mathrm{D} 8(n=177)$} \\
\hline & $\begin{array}{l}\text { Median } \\
\text { C-POMS/Rho }\end{array}$ & $p$ & $\begin{array}{l}\text { Median } \\
\text { C-POMS/Rho }\end{array}$ & $p$ & $\begin{array}{l}\text { Median } \\
\text { C-POMS/Rho }\end{array}$ & $p$ \\
\hline \multicolumn{7}{|c|}{ Tier 1 variables } \\
\hline \multicolumn{7}{|c|}{ Demographics } \\
\hline Age & 0.188 & 0.000 & 0.110 & 0.025 & 0.133 & 0.078 \\
\hline \multicolumn{7}{|l|}{ Age quartiles } \\
\hline $1(0-59)$ & 2.0 & 0.002 & 2.0 & 0.010 & 2.0 & 0.300 \\
\hline $2(60-68)$ & 3.0 & & 2.0 & & 3.0 & \\
\hline $3(69-74)$ & 3.0 & & 2.0 & & 4.0 & \\
\hline $4(\geq 75)$ & 4.0 & & 2.5 & & 3.0 & \\
\hline \multicolumn{7}{|l|}{ Age grp 2} \\
\hline$<65$ & 2.0 & 0.000 & 2.0 & 0.044 & 2.5 & 0.083 \\
\hline $65-74$ & 3.0 & & 2.0 & & 3.0 & \\
\hline$\geq 75$ & 4.0 & & 2.5 & & 3.0 & \\
\hline \multicolumn{7}{|l|}{ Age grp 3} \\
\hline$<70$ & 3.0 & 0.001 & 2.0 & 0.426 & 3.0 & 0.225 \\
\hline 70-79 & 3.0 & & 2.0 & & 3.0 & \\
\hline$>80$ & 5.0 & & 2.0 & & 3.0 & \\
\hline \multicolumn{7}{|l|}{ Gender } \\
\hline M & 3.0 & 0.024 & 2.0 & 0.016 & 3.0 & 0.215 \\
\hline F & 3.0 & & 3.0 & & 2.5 & \\
\hline \multicolumn{7}{|c|}{ Medical history } \\
\hline \multicolumn{7}{|l|}{ Diabetes } \\
\hline Y & 4.0 & 0.000 & 2.5 & 0.015 & 3.0 & 0.308 \\
\hline N & 3.0 & & 2.0 & & 3.0 & \\
\hline \multicolumn{7}{|c|}{ Cerebrovascular disease } \\
\hline Y & 4.0 & 0.028 & 3.0 & 0.023 & 4.0 & 0.219 \\
\hline N & 3.0 & & 2.0 & & 3.0 & \\
\hline \multicolumn{7}{|c|}{ Neurological history } \\
\hline Y & 4.0 & 0.103 & 3.0 & 0.016 & 4.0 & 0.553 \\
\hline $\mathrm{N}$ & 3.0 & & 2.0 & & 3.0 & \\
\hline \multicolumn{7}{|c|}{ Congestive heart failure } \\
\hline Y & 4.0 & 0.009 & 4.0 & 0.025 & 4.0 & 0.310 \\
\hline N & 3.0 & & 2.0 & & 3.0 & \\
\hline \multicolumn{7}{|c|}{ COPD/lung disease } \\
\hline Y & 4.0 & 0.005 & 3.0 & 0.012 & 3.0 & 0.380 \\
\hline N & 3.0 & & 2.0 & & 3.0 & \\
\hline \multicolumn{7}{|l|}{ Renal disease } \\
\hline Y & 5.0 & 0.064 & 5.0 & 0.001 & 5.0 & 0.025 \\
\hline $\mathrm{N}$ & 3.0 & & 2.0 & & 3.0 & \\
\hline
\end{tabular}


Table 3 Univariate analysis: tier 1 and 2 predictors of C-POMS summary score on D3, D5 and D8 (Continued)

\begin{tabular}{|c|c|c|c|c|c|c|}
\hline \multicolumn{7}{|l|}{ POSSUM ECG } \\
\hline Normal & 3.0 & 0.000 & 2.0 & 0.000 & 3.0 & 0.200 \\
\hline Sinus abnormal & 5.0 & & 4.0 & & - & \\
\hline AF & 4.0 & & 3.0 & & 3.0 & \\
\hline Any other abnormal & 5.0 & & 2.5 & & 2.0 & \\
\hline \multicolumn{7}{|l|}{ Paced } \\
\hline Y & 5.0 & 0.005 & 4.0 & 0.014 & 2.5 & 0.875 \\
\hline N & 3.0 & & 2.0 & & 3.0 & \\
\hline \multicolumn{7}{|l|}{ Dialysis } \\
\hline Y & 5.5 & 0.073 & 7.5 & 0.006 & 5.5 & 0.064 \\
\hline N & 3.0 & & 2.0 & & 3.0 & \\
\hline \multicolumn{7}{|l|}{ Pre-operative measurements } \\
\hline Body mass index $\left(\mathrm{kg} / \mathrm{m}^{2}\right)$ & 0.100 & 0.043 & 0.077 & 0.130 & 0.099 & 0.206 \\
\hline \multicolumn{7}{|l|}{ LVEF } \\
\hline Good & 3.0 & 0.013 & 2.0 & 0.011 & 3.0 & 0.013 \\
\hline Fair & 3.0 & & 2.0 & & 4.0 & \\
\hline Poor & 5.0 & & 5.0 & & 4.0 & \\
\hline \multicolumn{7}{|l|}{ Intra-operative } \\
\hline \multicolumn{7}{|l|}{ Type of surgery } \\
\hline CABG & 3.0 & 0.000 & 2.0 & 0.000 & 3.0 & 0.718 \\
\hline AVR & 4.0 & & 3.0 & & 3.0 & \\
\hline MVR & 5.0 & & 3.0 & & 3.5 & \\
\hline$C A B G+A V R$ & 4.0 & & 2.0 & & 3.0 & \\
\hline$A V R+M V R$ & 3.0 & & 3.0 & & 4.5 & \\
\hline$C A B G+M V R+A V R$ & 5.0 & & 5.0 & & 6.0 & \\
\hline Other & 5.0 & & 3.0 & & 3.0 & \\
\hline \multicolumn{7}{|l|}{ Urgency of op } \\
\hline Elective & 3.0 & 0.002 & 2.0 & 0.061 & 3.0 & 0.327 \\
\hline Urgent & 4.0 & & 2.0 & & 3.0 & \\
\hline \multicolumn{7}{|l|}{ Within first $12 \mathrm{~h}$} \\
\hline Systolic blood pressure (highest) & 0.002 & 0.959 & 0.026 & 0.599 & -0.089 & 0.238 \\
\hline \multicolumn{7}{|l|}{ Tier 2 variables } \\
\hline \multicolumn{7}{|l|}{ Demographics } \\
\hline \multicolumn{7}{|l|}{ Ethnicity } \\
\hline Caucasian & 3.0 & 0.052 & 2.0 & 0.008 & 3.0 & 0.532 \\
\hline Asian & 2.0 & & 1.0 & & 3.0 & \\
\hline Black & 5.0 & & 3.0 & & 3.0 & \\
\hline Other & 2.0 & & 3.0 & & 1.0 & \\
\hline \multicolumn{7}{|l|}{ Medical history } \\
\hline \multicolumn{7}{|l|}{ Smoking } \\
\hline Current & 2.0 & 0.048 & 2.0 & 0.395 & 3.0 & 0.753 \\
\hline Ex & 3.0 & & 2.0 & & 3.0 & \\
\hline Never & 3.0 & & 2.0 & & 3.0 & \\
\hline
\end{tabular}


Table 3 Univariate analysis: tier 1 and 2 predictors of C-POMS summary score on D3, D5 and D8 (Continued)

Family Hx CAD

Y

$\mathrm{N}$

3.0

4.0

Atrial arrhythmia

$$
\text { Y }
$$

N

Pre-operative measurements

Albumin
Haemoglobin
Heart rate
Weight

No diseased vessels

0

1

2

3

NYHA class

$\begin{array}{cc}1 & 2.0 \\ 2 & 3.0 \\ 3 & 4.0 \\ 4 & 5.0 \\ \text { CCSC class } & \end{array}$

0

1

2

3

4

Cardiomegaly

$$
\text { Y }
$$

N

Extracardiacarteriopathy

$$
\text { Y }
$$

N

Current medications

Diuretic

Intra-operative

Cardiopulmonary bypass
Not stated

$\begin{array}{ll}Y & 4.0 \\ N & 3.0\end{array}$

4.0

3.0

-0.210
-0.279
0.090
0.044

0.044

4.0

3.0

3.0

3.0

2.0

3.0

4.0

5.0

\begin{abstract}
3.0
\end{abstract}
2.0

3.0

3.0

4.0

5.0

3.0

3.0

5.0

3.0

4.0

3.0

3.0

2.0
0.002

2.0

2.0

0.021

3.0

2.0

0.000

$-0.144$

$-0.180$

0.179

0.042

0.369

0.011

3.0

2.0

2.0

2.0

0.001

1.0

2.0

3.0

2.5

0.041

3.0

2.0

2.0

2.0

2.0

0.000

3.0

3.0

3.0

0.003

3.0

2.0

0.003

3.0

2.0

0.001

2.0

1.0
0.019

3.0

3.0

0.007

3.0

3.0

0.004

$-0.183$

0.019

0.000

$-0.143$

0.058

0.000

0.080

0.294

0.399

0.101

0.186

0.000

3.0

2.0

2.0

3.0

0.002

3.0

0.001

3.0

3.0

5.0

0.042

3.0

2.0

3.0

3.0

4.0

0.000

4.0

3.0

3.0

0.004

4.5

3.0

0.147

N

0.072 
Table 3 Univariate analysis: tier 1 and 2 predictors of C-POMS summary score on D3, D5 and D8 (Continued)

\begin{tabular}{|c|c|c|c|c|c|c|}
\hline \multicolumn{7}{|c|}{ Within 1 st $12 \mathrm{~h}$ after surgery } \\
\hline Total drainage & 0.139 & 0.004 & 0.030 & 0.542 & 0.031 & 0.679 \\
\hline \multicolumn{7}{|l|}{ Post-operative (D1) } \\
\hline \multicolumn{7}{|l|}{ Heart rhythm } \\
\hline Sinus rhythm & 3.0 & 0.000 & 2.0 & 0.002 & 3.0 & 0.473 \\
\hline Sinus tachycardia & 2.5 & & 2.0 & & 2.5 & \\
\hline Sinus bradycardia & 4.0 & & 2.0 & & 4.0 & \\
\hline Atrial fibrillation & 5.0 & & 3.0 & & 4.0 & \\
\hline Other & 3.0 & & 2.0 & & 3.0 & \\
\hline \multicolumn{7}{|l|}{ Inotropes } \\
\hline Y & 4.0 & 0.004 & 3.0 & 0.070 & 3.0 & 0.923 \\
\hline $\mathrm{N}$ & 3.0 & & 2.0 & & 3.0 & \\
\hline
\end{tabular}

albumin, number of diseased vessels and number of saphenous vein grafts) were independently predictive of D8 score and these variables were not independent risk factors for any other post-operative day. Pre-operative haemoglobin, $12 \mathrm{~h}$ drainage, pre-operative weight and extra cardiacarteriopathy were tier 2 risk factors associated with D3 and D5 morbidity score, while pre-operative cardiomegaly and NYHA class were associated with D5 score only. Considering all time points, 12 -h total drainage, preoperative weight, extra-cardiac arteriopathy, age, diabetes, CABG surgery, pre-operative cardiomegaly and preoperative albumin level were independently predictive of C-POMS-defined post-operative morbidity outcome.

\section{Discussion}

We found that over two thirds (67.3\%) of variables, previously reported as a risk factor for post-operative morbidity, were associated with the new C-POMS (denoting TMB) on at least one post-operative day, with $40 \%$ being significant risk factors for two post-operative days and three (6.1\%) associated on all three postoperative days. From these results, there are four main findings of note. Firstly, we aimed to identify independent modifiable C-POMS risk factors amenable to therapeutic intervention. These were found to be pre-operative albumin and haemoglobin levels and weight-all tier 2 variables. Previously, pre-operative hypoalbuminaemia has been identified as a risk factor for post-operative delirium (Rudolph et al. 2009), reoperation for bleeding (Engelman et al. 1999), requirement for renal replacement therapy need (Engelman et al. 1999; Sato et al. 2015), increased ICU and hospital LOS (Engelman et al. 1999; Koertzen et al. 2013) and increased mortality (Engelman et al. 1999; Koertzen et al. 2013) cardiac surgery. While hypoalbuminaemia may be directly harmful, it may also mark other pathological states, such as anaemia, since pre-operative hypoalbuminaemia and anaemia are independently associated (Carrascal et al. 2010). Similarly, in cardiac surgery, pre-operative anaemia is associated with inhospital (De Santo et al. 2009; Hung et al. 2011) or 30-day (Boening et al. 2011) mortality, post-operative blood transfusion rate (De Santo et al. 2009; Hung et al. 2011; Boening et al. 2011), ICU (De Santo et al. 2009; Hung et al. 2011) and in-hospital LOS (De Santo et al. 2009), major adverse cardiovascular events (Boening et al. 2011), and renal complications (De Santo et al. 2009; Boening et al. 2011) than non-anaemic patients. However, evidence relating to whether pre-operative anaemia is associated with infection (Boening et al. 2011) or not (De Santo et al. 2009) is conflicting. There is less evidence relating preoperative weight to post-operative outcome. Weight loss after bariatric surgery improves hypertension, diabetes and dyslipidaemia (Batsis et al. 2007), although unintended preoperative weight loss $(\geq 10 \%)$ is also associated with prolonged hospital LOS (van Venrooij et al. 2008). Evidence of association is, of course, not the same as proof of causation. However, overall, taken with associated literature, our findings suggest pre-operative albumin, haemoglobin and weight to be candidates for pre-operative interventional studies with the aim of improving post-operative morbidity.

Secondly, we identified 17 independent risk factors for TMB on at least one post-operative day. Interestingly, except for renal dysfunction, the other seven tier 1 variables were all associated with D3 morbidity, with only three (diabetes, LVEF and CABG surgery) also being associated on D5 and none with D8 morbidity. Independent risk factors for D8 TMB lay entirely in tier 2 . Such findings perhaps suggest that different risk factors are associated with outcome on different post-operative days and that well-accepted risk factors may only be useful for predicting morbidity risk in the first few days of recovery. Patterns of morbidity are wellrecognised to differ with time after surgery, and it is likely that their drivers (whether they be intrinsic, environmental, or related to nascent morbidities) will also vary. Such factors 


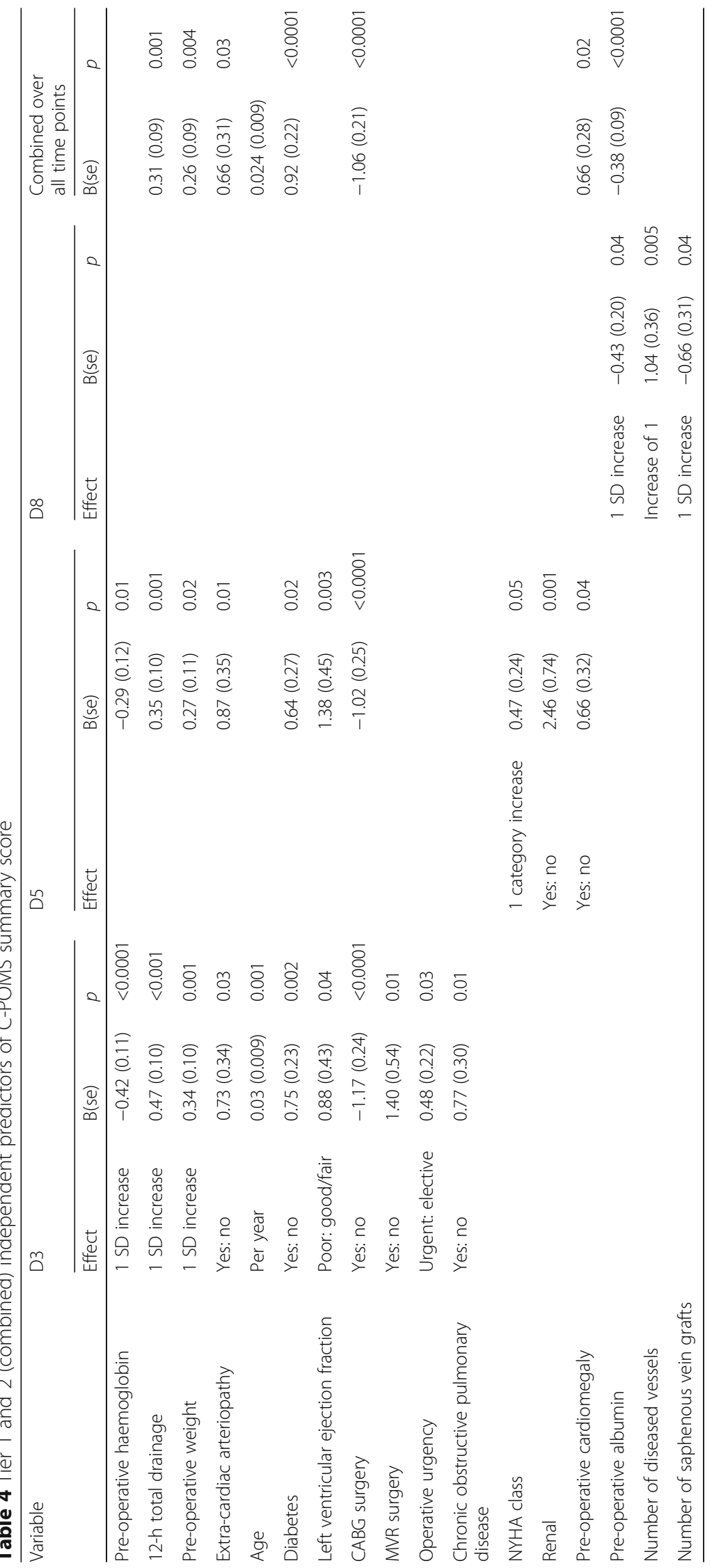


are likely to explain the fact that correlations between D3 and D5 with D8 data differed. Furthermore, this study adds to the evidence that pre-operative haemoglobin concentration, pre-operative weight, extra-cardiac arteriopathy, preoperative cardiomegaly, NYHA class, pre-operative albumin, number of diseased vessels, and number of saphenous vein grafts are independently associated with morbidity outcome.

Thirdly, as expected, the majority of tier 1 variables (those with significant evidence of association with postoperative morbidity) were associated with TMB on at least one post-operative day. While this is not clinically surprising, it does further validate C-POMS as a useful clinical tool in outcome assessment following cardiac surgery. In relation to the eight tier 1 variables that were not associated with TMB on any post-operative day, combining cerebrovascular accident and transient ischaemic attack to a combined cerebrovascular disease variable was associated with a higher C-POMS on D3 and D5, in line with other morbidity risk assessment models (Magovern et al. 1996; Huijskes et al. 2003; Higgins et al. 1992; Tuman et al. 1992) Furthermore, while hypertension has been independently associated with post-operative morbidity in some studies (for example, Fortescue et al. (2001) and Ivanov et al. (2006)), this has been disputed by others (Higgins et al. 1992; Hattler et al. 1994). However, our results pertaining to systolic blood pressure, previous cardiac surgery and diagnosed peripheral vascular disease are at odds with the literature.

Finally, this study also adds to the more limited data relating to some variables (those in tier 2) and their association with post-operative morbidity after cardiac surgery. Of these, $65.4 \%$ were associated with C-POMS TMB score on at least one post-operative day, while preoperative albumin measurement and NYHA class were risk factors for all three post-operative days. Furthermore, this study also confirmed the findings of previous studies suggesting that unstable angina or recent myocardial infarction (Tuman et al. 1992; Hattler et al. 1994) and pre-existing liver disease (Higgins et al. 1992) are not associated with post-operative morbidity. However, while our study corroborated that of Magovern et al. (Magovern et al. 1996) showing that pre-operative atrial arrhythmia and cardiomegaly are associated with morbidity outcome (Magovern et al. 1996), such results conflict with those found by Hattler and colleagues (Hattler et al. 1994).

There are four main limitations of this study. Firstly, there was no consistent definition of post-operative morbidity used in the pre-operative risk assessment models reported by others. Thus, a wide-range of variables to predict such diversely described outcomes were identified. However, over two-thirds of all variables were found to be associated with TMB, as defined by CPOMS, on at least one post-operative day suggesting that C-POMS is a valid measure of morbidity. Secondly, from the pre-operative risk assessment models, it is difficult to assess what variables were not found to be associated with post-operative morbidity. Most studies did not report variables for which no association with morbidity was identified, due to the often large number $(>100)$ of variables included. We have made our statistically nonsignificant results available to redress this balance and to aid in the evaluation of this (and other) tools. Thirdly, 14 risk factors identified in the pre-operative risk assessment models were available within this study dataset. Some variables, such as transplantation and ventricularseptal defect, were not available as these surgery types were not included in the study, while the others were non-routinely recorded items. Aside from catastrophic states, the variables not included were all tier 2 variables and in the main were only associated with outcome in one previous study. Finally, analysis to identify risk predictors for C-POMS TMB on D15 could not be conducted due to there being too few participants remaining in the hospital on D15 $(n=45)$. However, this could be the subject of future work.

\section{Conclusions}

Post-operative morbidity is increasingly accepted as an independent quality of care indicator, with approximately $80 \%$ of patients wanting to be informed of all the risks associated with surgery (Larobina et al. 2007). Thus, in obtaining operative consent, patients should be told about 'less serious side effects and complications' (General Medical Council 2008). C-POMS is a tool that permits such morbidity assessment and TMB scoring at several time points after cardiac surgery, allowing both broad and detailed tracking of morbidities. We have found that pre-operative albumin, haemoglobin and weight are potentially modifiable risk factors for which the investigation of the effect of therapeutic interventions on C-POMS outcome is warranted. Furthermore, we have identified, for the first time, that risk factors differ for different post-operative days. Further work should include the identification of novel risk factors of C-POMS TMB score for each post-operative day, and the identification of risk factors associated with each C-POMS morbidity type to identify the risk factors associated with D15 C-POMS summary score. Additionally, further validation of these results could be sought in a subsequent C-POMS dataset. Such identification of risk factors for C-POMS TMB may aid patient group and individual risk stratification and potentially reduce healthcare costs.

\section{Additional files}

Additional file 1: Variables included in pre-operative prediction models of post-operative morbidity. (DOCX $241 \mathrm{~kb}$ )

Additional file 2: Univariate analysis: tier 1 and 2 not predictive of CPOMS summary score on D3, D5 and D8. (DOCX 20 kb) 


\section{Abbreviations}

AVR: Aortic valve replacement; CABG: Coronary artery bypass graft; CAD: Coronary artery disease; CCSC: Canadian cardiovascular score; COPD: Chronic obstructive pulmonary disease; C-POMS: Cardiac Post-Operative Morbidity Score; CRP: Creactive protein; D3 (D5, D8, D15): Day 3, (day 5, day 8, day 15); ICU: Intensive care unit; INR: International normalised ratio; IV: Intravenous; LOS: Length of stay; LVEF: Left ventricular ejection fraction; MI: Myocardial infarction; MVR: Mitral valve replacement; NYHA: New York Heart Association; OPA: Out-patient appointment; OT: Occupational therapy; TMB: Total morbidity burden; UK: United Kingdom; USA: United States of America

\section{Acknowledgements}

The authors would like to thank all members of the protocol development group (PDG) and the patients who generously gave their time and consent to participate in the C-POMS study.

\section{Funding}

This work was unfunded, but Professors Hugh Montgomery and Michael Mythen were supported by the National Institute for Health Research University College London Hospitals Biomedical Research Centre.

\section{Availability of data and materials}

Informed consent was not obtained for publication of patient data as publication of the dataset was not anticipated at the time of the initial C-POMS study. Thus, the data that support the findings of this study are available from JS but restrictions apply to the availability of these data, which were used under license for the current study, and so are not publicly available. Data are however available from the authors upon reasonable request and with permission of an appropriate research ethics committee and information governance (where appropriate) approvals.

\section{Authors' contributions}

Each author has fulfilled the ICMJE guidelines to qualify as an author. According to the ICMJE guidelines, to qualify as an author, one should have made substantial contributions to conception and design (JS, MM, HM) or acquisition of data (JS), or analysis (JC) and interpretation of data (JS, MM, HM); been involved in drafting the manuscript or revising it critically for important intellectual content (ALL); and given final approval of the version to be published (ALL). Each author has participated sufficiently in the work to take public responsibility for the appropriate portions of the content and have agreed to be accountable for all aspects of the work in ensuring that questions related to the accuracy or integrity of any part of the work are appropriately investigated and resolved.

\section{Competing interests}

The authors declare that they have no competing interests.

\section{Authors' information}

Not included.

\section{Consent for publication}

Not applicable.

\section{Ethics approval and consent to participate}

The National Research Ethics Committee London-Bentham (Chair Professor David Katz) gave ethics permission for this work in the Cardiac Post-Operative Morbidity Score (C-POMS) study (protocol amendment 7) on 6 September 2011 (reference 04/Q0502/73). All patients included in this study gave written informed consent to participate.

\section{Author details}

'St Bartholomew's Hospital, Barts Health NHS Trust, London, UK. ${ }^{2}$ Institute for Sport, Exercise and Health, University College London, 1st Floor 170 Tottenham Court Rd, London W1T 7HA, UK. ${ }^{3}$ Centre for Cardiovascular Genetics, University College London, London, UK. ${ }^{4}$ Department of Anaesthesia, University College London Hospitals NHS Trust, London, UK

Received: 30 July 2016 Accepted: 24 January 2017

Published online: 14 February 2017

\section{References}

Batsis JA, Romero-Corral A, Collazo-Clavell ML, Sarr MG, Somers VK, Brekke L, LopezJimenez F. Effect of weight loss on predicted cardiovascular risk: change in cardiac risk after bariatric surgery. Obesity.(Silver.Spring). 2007;15(3):772-84.

Boening A, Boedeker RH, Scheibelhut C, Rietzschel J, Roth P, Schonburg M. Anemia before coronary artery bypass surgery as additional risk factor increases the perioperative risk. AnnThoracSurg. 2011;92:805-10.

Bridgewater B, Kinsman R, Ireland on behalf of the S for CS in GB and: Demonstrating quality: the sixth National Adult Cardiac Surgical database report. Henley-on-Thames, UK: Dendrite Clinical Systems Ltd; 2008.

Brown PP, Kugelmass AD, Cohen DJ, Reynolds MR, Culler SD, Dee AD, Simon AW. The frequency and cost of complications associated with coronary artery bypass grafting surgery: results from the United States Medicare program. Ann Thorac Surg. 2008;85(6):1980-6.

Carrascal Y, Maroto L, Rey J, Arévalo A, Arroyo J, Echevarría JR, Arce N, Fulquet E. Impact of preoperative anemia on cardiac surgery in octogenarians. Interact Cardiovasc Thorac Surg. 2010;10:249-55.

De Santo L, Romano G, Della Corte A, de Simone V, Grimaldi F, Cotrufo M, de Feo M. Preoperative anemia in patients undergoing coronary artery bypass grafting predicts acute kidney injury. J Thorac Cardiovasc Surg. 2009;138:965-70.

Dissemination Centre for Reviews and Dissemination. CRD Report 4 (2nd Edition). Undertaking systematic reviews of research on effectiveness:CRD's guidance for those carrying out or commissioning reviews. 2001.

Dupuis JY, Wang F, Nathan H, Lam M, Grimes S, Bourke M: The cardiac anesthesia risk evaluation score: a clinically useful predictor of mortality and morbidity after cardiac surgery. Anesthesiology. 2001;94(2):194-204.

Engelman DT, Adams DH, Byrne JG, Aranki SF, Collins Jr. JJ, Couper GS, Allred EN, Cohn LH, Rizzo RJ. Impact of body mass index and albumin on morbidity and mortality after cardiac surgery. J Thorac Cardiovasc Surg. 1999;118(5):866-73.

Fortescue EB, Kahn K, Bates DW. Development and validation of a clinical prediction rule for major adverse outcomes in coronary bypass grafting. Am J Cardiol. 2001;88(11):1251-8.

General Medical Council. Consent: patients and doctors making decisions together. 2008.

Guyatt GH, Kirshner B, Jaeschke R. Measuring health status: what are the necessary measurement properties? J Clin Epidemiol. 1992;45(1):1341-5.

Hattler BG, Madia C, Johnson C, Armitage JM, Hardesty RL, Kormos RL, Pham SM, Payne DN, Griffith BP. Risk stratification using the Society of Thoracic Surgeons Program. Ann Thorac Surg. 1994;58(5):1348-52.

Higgins TL, Estafanous FG, Loop FD, Beck GJ, Blum JM, Paranandi L. Stratification of morbidity and mortality outcome by preoperative risk factors in coronary artery bypass patients. A clinical severity score. JAMA. 1992;267(17):2344-8.

Huijskes RV, Rosseel PM, Tijssen JG. Outcome prediction in coronary artery bypass grafting and valve surgery in the Netherlands: development of the Amphiascore and its comparison with the Euroscore. Eur J Cardiothorac Surg. 2003;24(5):741-9.

Hung M, Besser M, Sharples LD, Nair SK, Klein AA. The prevalence and association with transfusion, intensive care unit stay and mortality of pre-operative anaemia in a cohort of cardiac surgery patients. Anaesthesia. 2011;66:812-8.

Ivanov J, Borger MA, Rao V, David TE. The Toronto Risk Score for adverse events following cardiac surgery. Can J Cardiol. 2006;22(3):221-7.

Kirshner B, Guyatt G. A methodological framework for assessing health indices. J Chronic Dis. 1985:38(1):27-36.

Koertzen M, Punjabi P, Lockwood G. Pre-operative serum albumin concentration as a predictor of mortality and morbidity following cardiac surgery. Perfusion. 2013;28:390-4.

Larobina ME, Merry CJ, Negri JC, Pick AW. Is informed consent in cardiac surgery and percutaneous coronary intervention achievable? ANZ J Surg. 2007;77(7):530-4.

Magovern JA, Sakert T, Magovern GJ, Benckart DH, Burkholder JA, Liebler GA Magovern Sr. GJ. A model that predicts morbidity and mortality after coronary artery bypass graft surgery. J Am Coll Cardiol. 1996;28(5):1147-53.

Rudolph JL, Jones RN, Levkoff SE, Rockett C, Inouye SK, Sellke FW, Khuri SF, Lipsitz LA, Ramlawi B, Levitsky S, Marcantonio ER. Derivation and validation of a preoperative prediction rule for delirium after cardiac surgery. Circulation. 2009;119(2):229-36

Sanders J, Keogh BE, Van der Meulen J, Browne JP, Treasure T, Mythen MG, Montgomery HE. The development of a postoperative morbidity score to assess total morbidity burden after cardiac surgery. J Clin Epidemiol. 2012;65:423-33.

Sato Y, Kato TS, Oishi A, Yamamoto T, Kuwaki K, Inaba H, Amano A. Preoperative factors associated with postoperative requirements of renal replacement therapy following cardiac surgery. Am J Cardiol. 2015;116:294-300. 
Shahian DM, O'Brien SM, Normand SL, Peterson ED, Edwards FH. Association of hospital coronary artery bypass volume with processes of care, mortality, morbidity, and the Society of Thoracic Surgeons composite quality score. J Thorac Cardiovasc Surg. 2010;139(2):273-82.

Society of Thoracic Surgeons: Online STS risk calculator. http://riskcalc.sts.org/ stswebriskcalc/\#/. Accessed 01 Feb 17.

Tuman KJ, McCarthy RJ, March RJ, Najafi H, Ivankovich AD. Morbidity and duration of ICU stay after cardiac surgery. A model for preoperative risk assessment. Chest. 1992;102(1):36-44.

van Venrooij LM, De VR, Borgmeijer-Hoelen MM, Haaring C, de Mol BA. Preoperative unintended weight loss and low body mass index in relation to complications and length of stay after cardiac surgery. Am J Clin Nutr. 2008; 87(6):1656-61.

Weiser TG, Regenbogen SE, Thompson KD, Haynes AB, Lipsitz SR, Berry WR, Gawande AA. An estimation of the global volume of surgery: a modelling strategy based on available data. Lancet. 2008;372(9663):139-44.

Submit your next manuscript to BioMed Central and we will help you at every step:

- We accept pre-submission inquiries

- Our selector tool helps you to find the most relevant journal

- We provide round the clock customer support

- Convenient online submission

- Thorough peer review

- Inclusion in PubMed and all major indexing services

- Maximum visibility for your research

Submit your manuscript at www.biomedcentral.com/submit
Biomed Central 